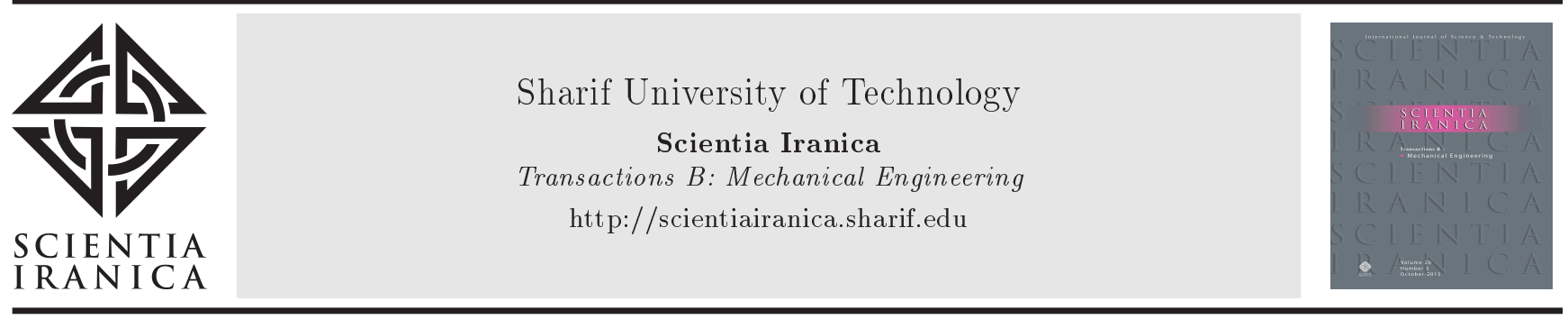

Research Note

\title{
Design of mixed flow pump impeller blade using mean streamline theory and its analysis
}

\author{
D. Zindani, A.K. Roy, and K. Kumar* \\ Department of Mechanical Engineering, Birla Institute of Technology, Mesra, Ranchi, 835215, India.
}

Received 22 January 2017; received in revised form 15 January 2018; accepted 11 August 2018

\author{
KEYWORDS \\ Mixed flow pump \\ impeller blade; \\ AutoCAD; \\ Solid works premium; \\ ANSYS; \\ Mean streamline \\ theory; \\ Free vortex theory.
}

\begin{abstract}
Given the importance of blade design in the effective performance of a mixed flow pump, the present work demonstrates the designing of the mixed flow pump impeller blade using the almost unexplored mean streamline theory. The mean streamline theory, though used sparingly, was found suitable to give comparable results to those of other templates of design. The design process was carried out in AutoCAD 2013 and Solid Works Premium 2014 software. The analysis of equivalent stress, equivalent elastic strain, Total deformation, and the directional deformation was carried out in ANSYS 2014 for different construction materials of the blade, i.e., stainless steel, titanium alloy, bronze, and copper alloy. Total deformation was found to be maximum for the impeller blade made from titanium alloy, whereas the equivalent stress and strain was found to be the least for the titanium alloyed impeller blade. Further, a comparison analysis of the equivalent stresses in blade designed was carried out using mean streamline theory and free vortex theory. It was observed that the equivalent stress in impeller blade designed using free vortex theory was lower than that designed using mean streamline theory.
\end{abstract}

2020 Sharif University of Technology. All rights reserved.

\section{Introduction}

A pump functions to convert the mechanical form of energy to hydraulic energy. Pumps can be classified into radial, axial, and mixed forms based on the configuration of the impeller and the specific speed of the pump. Rotary mechanism forms the basis of the working principle of a centrifugal pump. The combination of centrifugal action and lifting action of the liquid of the vane produces the desired head in the case of a mixed flow pump. In the case of the mixed flow pump, liquid enters the pump in the axial direction, whereas it exits the pump both in the radial and axial

*. Corresponding author. Tel.: +919431597463

E-mail address: kkumar@bitmesra.ac.in (K. Kumar)

doi: $10.24200 /$ sci. 2018.20829 directions. Thus, a mixed flow pump encompasses the advantages of both radial and axial flow pumps. The advantages lend unique operating characteristics to the mixed flow pump and versatility in their operation. The versatile characteristics make a mixed flow pump suitable for a wide range of applications such as flood control, power station cooling systems, etc. Scientific community faces acute challenge for extending the operating range of mixed flow pumps owing to their versatile and reliable characteristics. A large number of geometric parameters are involved in designing mixed flow pumps. Further, performance prediction is a relatively cumbersome task.

Various design templates have been used over the years for designing the pump impeller blade. The first design template for the mixed flow pump was put forth by Wislicensus [1], which was later on modified by Myles [2], Stepanoff [3], Neumann [4], Gahlot 
and Nyiri [5] who developed and suggested their own design templates for mixed flow pumps. Experimental results were used by Varchola and Hlbocan [6] in the development of design template for a mixed flow pump.

The inverse time marching method [7], the pseudo-stream function method [8], and the Fourier expansion singularity method [9] were some of the real $3 \mathrm{D}$ inverse design methods. However, the proposed 3D inverse design methods, such as inverse time marching method and pseudo-stream function methods, take a significant amount of time for the development of design, and also difficulties are encountered while correlating the various design parameters with the geometry of the blade. On the other hand, the Fourier expansion singularity method confronted the convergence problem. To address the major challenge of time, a quasi-3D method was proposed [10] that performed a blade-to-blade solution. Further, the method uses one representative surface from hub-toshroud of the impeller blade. The approach resulted in significant computational time saving. In view of saving computational time, Anagnostopoulos [11] developed a fast numerical method for the analysis of fluid flow and, hence, designing the pump impeller blades. Assumptions of inviscid fluid are considered while developing all of the above models for designing a pump impeller.

Computational fluid dynamics was employed by Li et al. [12] for carrying out the optimum design of the pump impeller blade. Spalart-Allmaras turbulent model was a basis used for simulating the threedimensional flow field in the whole flow passage of a mixed-flow pump. The simulation results aided in establishing the reason as to why the flow rate of the pump was not able to match the design requirements. Similar simulations of a low-specific-speed high-speed centrifugal pump were carried out by Jafarzadeh et al. [13] using CFD code. The governing equations related to flow field were solved using commercial CFD code and, then, the results were used for creating the optimum design of the pump. Results of similar simulations were obtained using CFD code and used for achieving an optimum design of the pump impeller blade by Chaudhari et al. [14] and Desai and Naik [15].

Researchers have made numerous attempts to study the effect of various forces on the blade. Numerical investigations of the hydrodynamic radial forces for several flow rates in a mixed-flow pump were carried out by Mingxiong et al. [16]. The analysis was conducted using CFD simulations and validations. Significant influence on hydrodynamic radial forces and pressure fluctuations of the recirculation flow pattern under part-load conditions was reported by the study. Dynamic and static stability of the rotating impeller blade was analyzed for axial periodic force by Sakar and Sabuncu [17]. Blade was found to be more stable for increasing rotational speed and disk radius. $\mathrm{Li}$ et al. [18] investigated the erosion effect of the water drop on a turbine blade. The damage to the piping system because of the pressure fluctuations arising from excitations of the centrifugal pump at the blade passing frequency was studied by Kaneko and Hayashi [19]. Kikuyama et al. [20] investigated the effect of the inlet swirl on static pressure acting on impeller blades of a centrifugal pump.

Performance enhancement is another crucial factor that needs to be considered while carrying out the optimum design of the pump. Conducting analysis to enhance the performance behavior of a single flow pump for the unsteady flow behavior was carried out by Shou-qi et al. [21]. The oscillations inducing an impeller with unsteady flow were numerically and experimentally investigated by Pei et al. [22]. Structural and thermal analyses are also crucial in deciding the performance of a pump. In this regard, a number of researchers [23-25] such as Ramamurti and Balasubramanium [26], Jonker and Essen [27], Lemeš and Nermina [28], Bhope and Padole [29], Arewar and Bhope [30], and Das et al. [31] have made their efforts and studied the stresses for highly complex blade profiles of a wide range of turbo machinery. Kan et al. [32] conducted dynamic stress analysis of the impeller blade based on bidirectional fluid-structure interaction. CFD analysis of the centrifugal pump impeller for the performance enhancement was carried out by Kumar et al. [33]. Kocaaslan et al. [34] numerically investigated the effect of the number of blades on the pump performance. Design and stress analysis for impeller blade designed using a free vortex theory was carried out by Srivastava et al. [35]. The von Mises stresses were analyzed and compared in the case of an impeller blade of mixed flow pump at different positions in the meridional annulus.

Owing to the importance of efficient design and performance analysis of the pumps, in the present work, the design of the impeller blade of the mixed flow pump using mean streamline method was carried out. The 3D modeling was done by Solid Works Premium Software 2014. The analysis of equivalent stress, maximum principal stress, equivalent elastic strain, maximum principal elastic strain, minimum principal elastic strain, total deformation, and directional deformation was carried out for the blade designed using mean streamline theory. A comparative analysis of the equivalent stress in the blade designed using free vortex method was carried out. Furthermore, a comparative analysis was carried out for different construction materials of the blade, i.e., titanium alloy, stainless steel, copper alloy, and bronze. Specifications of the mixed flow pump under consideration were kept identical for both methods of design templates. 
Analysis of stress was carried out by commercially available finite element software, i.e., ANSYS 14.0.

\section{Specifications of pump}

The design and its analysis were carried out for a pump with a specific speed $\left(N_{S}\right)$ of $105.74 \mathrm{rpm}$, assuming that: $D_{2 i}=250 \mathrm{~mm}, \eta=0.76, P=15 \mathrm{~kW}$.

The following assumptions were also considered for designing the blade:

- One-dimensional approach;

- Constant meridional velocities at inlet and outlet impeller sections;

- No meridional curvature;

- Straight hub to shroud contours;

- Un-shrouded impeller.

\section{Specific speed}

Specific speed is defined as the speed in revolutions per minute at which a geometrically similar impeller would operate if it were of such a size as to deliver one cubic meter per second against one meter of hydraulic head. Specific speed characterizes the performance of a pump that handles particular fluid and is given by Eq. (1):

$$
N_{S}=\frac{N \sqrt{Q}}{(H)^{3 / 4}}
$$

In the present work, the blade of the mixed flow pump was used to produce a discharge $(Q)$ of $0.125 \mathrm{~m}^{3} / \mathrm{sec}$, working under a hydraulic head $(H)$ of $5 \mathrm{~m}$ and a rotational speed of $1000 \mathrm{rpm}$. The operating conditions are inserted in Eq. (1), yielding a specific speed $\left(N_{S}\right)$ of $105.74 \mathrm{rpm}$. The impeller blade was designed with respect to the linear distribution of pressure from inlet to outlet and from hub to tip.

\section{Initial design Layout of a mixed flow pump impeller blade}

Figure 1 delineates the steps for 3D modeling the impeller blade using mean streamline theory.

Stepanhoff [3] plotted the variation of the diameter ratio $(e)$ with a specific speed $\left(N_{S}\right)$ of the pump. The variation was depicted in [36]. The calculations for the initial design parameters of the blade, i.e., $D_{2 i}$, $D_{1 o}, D_{2 o}$, and $D_{m o}$, were tabulated in [36].

By taking into account the initial design parameters of the blade, the layout of the blade was obtained in AutoCAD 2013 by choosing a suitable semi-cone

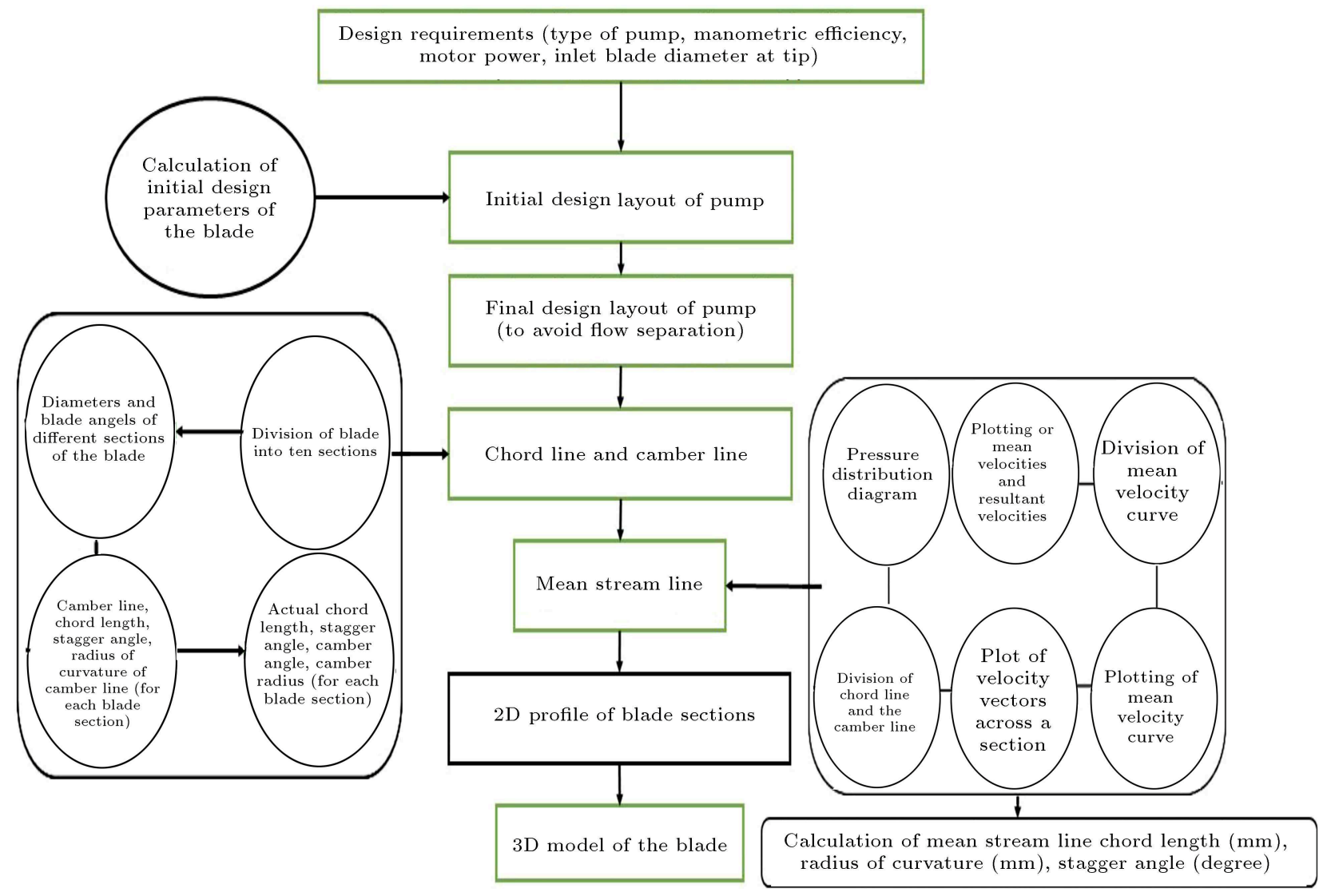

Figure 1. Design methodology for 3D modeling of the blade. 
angle $(\psi / 2)$ of $30^{\circ}$. The layout was delineated in [36] and used for the calculation of the remaining initial parameters of the blade. The values obtained were tabulated in [37].

\section{Final design layout of the mixed flow pump impeller blade with respect to flow separation}

When the boundary layer travels to a far-off distance in the backdrop of adverse pressure gradient and the speed of boundary layer falls to zero relative to the object, then the conditions become favorable for flow separation to take place. Under such conditions, the fluid flow detaches itself from the surface of the object and takes the form of vortices and eddies. Vibrations in structure may result in the aftermath of the shedding vortices, and serious failure occurs when the frequency of the shedding vortices matches the resonance frequency of the structure. Therefore, it becomes necessary to avoid flow separation in the impeller blade of the pump. To remedy this effect, Myles [2] suggested that the ratio $D_{m o} / D_{m i}$ should be 1.20. Final geometrical parameters of the impeller blade were then obtained to avoid the phenomenon of flow separation. The calculations were shown in [36]. The final layout of the impeller blade was then obtained using the calculated values, as delineated in Figure 2.

\section{Design methodology}

The 3D model of the impeller blade was obtained following the design steps below.

\subsection{Calculation of camber line chord length, stagger angle, and radius of curvature of the camber line}

The blade (A- $\left.\mathrm{A}^{\prime}-\mathrm{J}^{\prime}-\mathrm{J}\right)$, shown in Figure 2, is divided into ten sections. For each one of the sections, camber line chord length $\left(C^{\prime}\right)$ and its stagger angle $(\lambda)$ were obtained and depicted in [36]. Calculations of the inlet

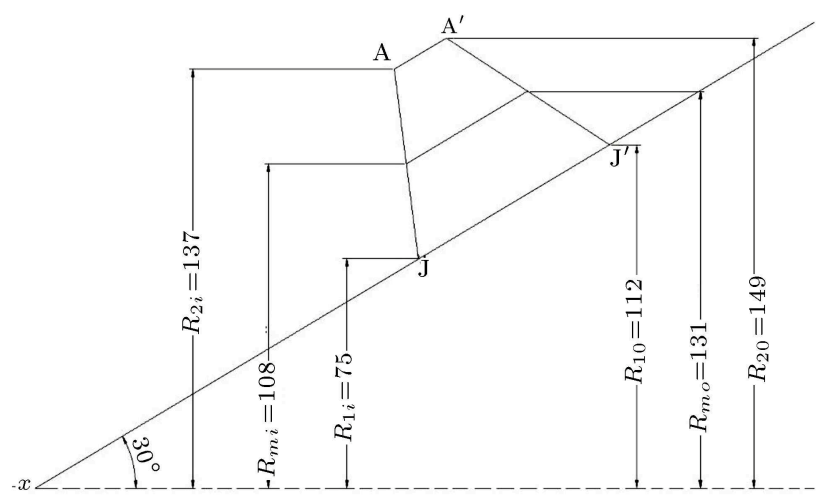

Figure 2. Final layout of the pump impeller blade $\left(\mathrm{AA}^{\prime} \mathrm{J}^{\prime} \mathrm{J}\right)$. and outlet circumferential velocities, inlet velocity of flow, the fluid inlet angle ' $\theta_{i}$ ', the tangential component of the velocity ' $V_{w o}$ ', the fluid outlet angle ' $\phi$ ', the slip velocity $\left(V_{S}\right)$ resulting from the generation of eddies, the modified outlet blade angle, the mean blade angle ' $\alpha_{m}$ ', pitch ' $S$ ', and the inlet $D_{i}(\mathrm{~mm})$ and outlet $D_{o}$ $(\mathrm{mm})$ diameters were shown in [37]. These calculations were carried out for different sections of the blade. The results obtained were tabulated in [36]. The actual chord length, camber line and its stagger angle were obtained for different blade sections using an iterative procedure, until the difference between the old stagger angle and the modified stagger angle would reach $0.01^{\circ}$. The radius of curvature of the camber line $R$ was also obtained for different sections of the blade. These calculations were also tabulated in [36]. By using AutoCAD 2013, the chord and the camber lines were plotted for different sections of the blade, and the plot is shown in [37]. Deviation rules were followed while performing the calculations [37].

\subsection{Chord length and Radius of curvature of mean stream curve}

The flow velocity can be geometrically represented through streamlines. The velocity vector can be defined in terms of time and space coordinates in accordance with the Eulerian method. A streamline is obtained when a space curve is drawn in such a way that it is tangent to velocity vector at a fixed instant of time. Therefore, the Eulerian method gives a series of instantaneous streamlines of the state of motion.

Streamlines were obtained for different sections of the impeller blade in the present work. The procedural steps followed to obtain a streamline for a particular section of the blade were delineated in [36]. Mean streamline for section $\mathrm{J}_{-} \mathrm{J}^{\prime}$ of the impeller blade is depicted in Figure 3 [37].

The above procedural steps, once followed, result in different geometric parameters for different sections of the impeller blade, i.e., length of chord for mean streamline $\left(C^{\prime}\right)$, stagger angle $(\lambda)$ for the mean streamline chord, and the radius of curvature of the mean

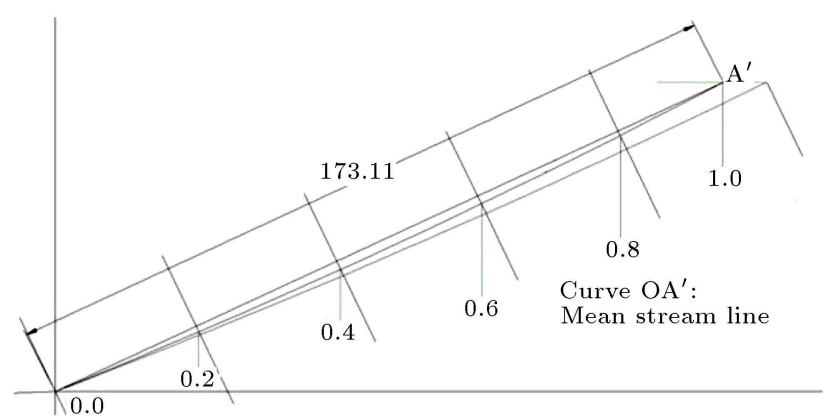

Figure 3. Plot of mean stream line at section $\mathrm{J}_{-} \mathrm{J}^{\prime}$ of the impeller blade. 
streamline curve $(R)$. The measured results were tabulated in $[37,38]$.

Curve fitting was done for the mean streamline chord length and, also, for its radius of curvature to obtain a smooth blade profile, and the final results were tabulated and depicted in $[37,38]$.

\subsection{D profile of the blade section in solidworks premium 2014}

To generate a complete blade profile, the coordinates of the upper and lower surface of the mean streamline are required to be calculated. The calculations were shown in [37]. Figure 4 depicts the $2 \mathrm{D}$ profile for a particular blade section of the impeller blade.

\subsection{D modeling of the pump impeller blade}

The procedural steps of Subsections $6.1-6.3$ were followed, and two-dimensional blade profiles of different sections of the blade were obtained. Different blade profiles of the impeller blade were stacked together at their respective stagger angles, and the 3D model of the impeller blade was obtained, as depicted in Figure 5.

\section{Analysis of the blade in ANSYS 14.0}

Given the importance of blade stresses, the analysis of the stresses needs to be highly accurate. The calculation of stresses and strains in a mixed flow pump impeller blade is extremely complicated due to the complex loading characteristics and the geometry of the blade. To perform an accurate estimation of the stresses in the blades, the stress values are required to be validated in comparison with the calculated values. To accomplish the above, a simplified method of stress

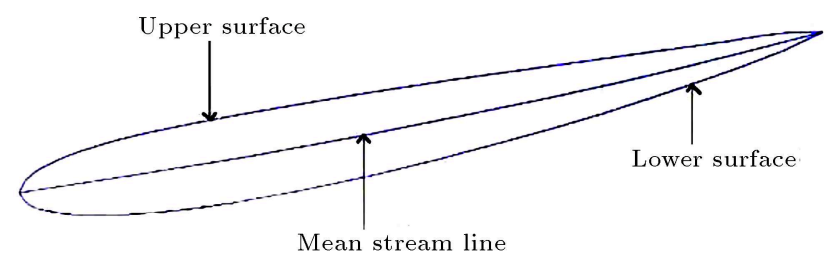

Figure 4. 2D profile of a blade section $J J^{\prime}$ of the blade $\left(\mathrm{A}-\mathrm{A}^{\prime}-\mathrm{J}^{\prime}-\mathrm{J}\right)$.

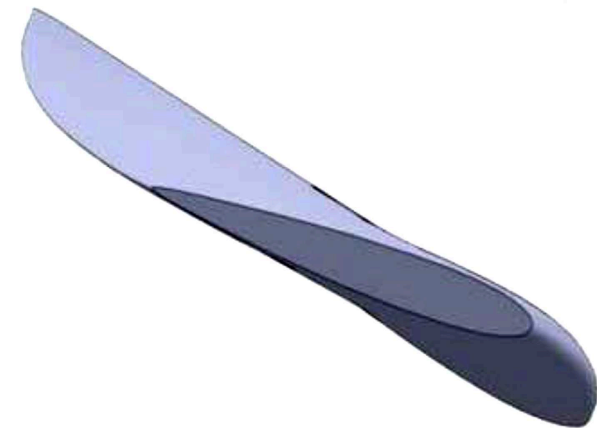

Figure 5. 3D modeled pump impeller blade with its front view. validation among the calculated and numerically predicted values was carried out by replacing the twisted blades with an equivalent plate of rectangular crosssection, which acts as a cantilever. The material properties and the volume of both plate and blade were kept identical. The theoretical calculation of von Mises stress was carried out through Eqs. (2)-(10). It is assumed that each blade of the mixed flow pump impeller acts as a cantilever.

The dimensions of the equivalent plate are $58 \mathrm{~mm} \times 162.72 \mathrm{~mm} \times 10.41 \mathrm{~mm}$. The torque applied to the plate is calculated as follows:

$$
T=\frac{w l^{2}}{2}
$$

Moreover:

$$
T=\frac{60 P}{2 \Pi N Z}
$$

From Eqs. (2) and (3), Eq. (4) is obtained:

$$
w=\frac{60 P}{\Pi Z N l^{2}},
$$

where:

$$
P=20 \mathrm{~kW}, \quad N=1000 \mathrm{rev} / \mathrm{min}, \quad Z=8 .
$$

Therefore:

$$
w=10588 \mathrm{~N} / \mathrm{m} \text {. }
$$

For a rectangular beam in pure bending, the shear stress is given by Eq. (5):

$$
\tau=F \frac{A y}{I b} .
$$

By substituting the respective values, the shear stress calculated is given by Eq. (6):

$$
\tau=2750 \mathrm{~N} / \mathrm{m}^{2} \text {. }
$$

The bending stress, $\sigma_{b}$, is calculated using Eq. (7):

$$
\sigma_{b}=\frac{M y}{I}=\frac{3 w l^{2}}{b h^{2}} \text {. }
$$

The values obtained are substituted in Eq. (6) to obtain the value of $\sigma_{b}$ :

$$
\sigma_{b}=12.08 \times 10^{6} \mathrm{~N} / \mathrm{m}^{2} .
$$

Distortion energy theory is then used to obtain the equivalent stress, according to which a ductile solid will yield when the distortion energy density reaches a critical value for that material. Eq. (8) is used to calculate the distortion energy density associated with yielding: 


$$
U_{d}=\frac{1+\nu}{3 E} \sigma_{y}^{2}
$$

Thus, the energy density given in Eq. (8) is a critical value of the distortion energy density for the material. Then, according to von Mises's failure criterion, the material under multi-axial loading will yield when the distortion energy is equal to or greater than the critical value for the material:

$$
\begin{aligned}
& \frac{1+\nu}{3 E} \sigma_{V M}^{2}=\frac{1+\nu}{3 E} \sigma_{Y}^{2}, \\
& \therefore \sigma_{V M} \geq \sigma_{y},
\end{aligned}
$$

in terms of the general stress components:

$$
\begin{aligned}
& \sigma_{V M}=\sqrt{\sigma_{b}^{2}+3 \tau^{2}}, \\
& \therefore \sigma_{V M}=12.8 \mathrm{MPa} .
\end{aligned}
$$

Once the value of the von Mises stress was calculated for the plate, FEM convergence test would be carried out on the plate with different sizes of the element to determine the optimum size of the element using ANSYS 14.0. By applying an optimum element size, the numerical stress analysis of the pump impeller blades was carried out. The von Mises stresses were calculated considering the material properties of stainless steel. The optimal size of the element was obtained as $0.52 \mathrm{~mm}$. Here, tetrahedral element was used for the analysis. Spanwise variation of von Mises stress for the plate with an element size of $0.52 \mathrm{~mm}$ is shown in Figure 6.

Since the impeller blade was subjected to surface force density, the calculation of the surface force density was conducted. This calculation was done owing to the complex nature of the blade's geometrical profile. This

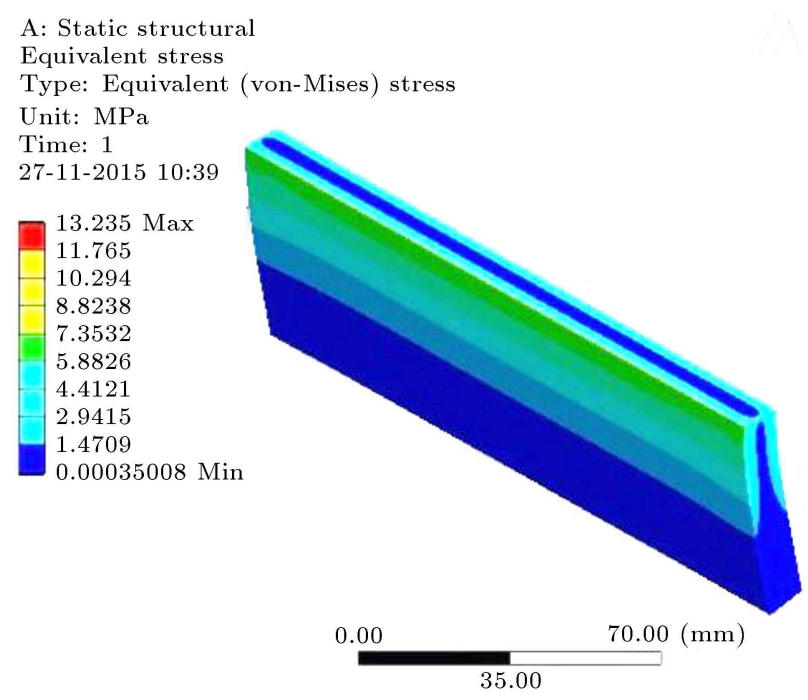

Figure 6. Span-wise distribution of von Mises stress for stainless steel plate.

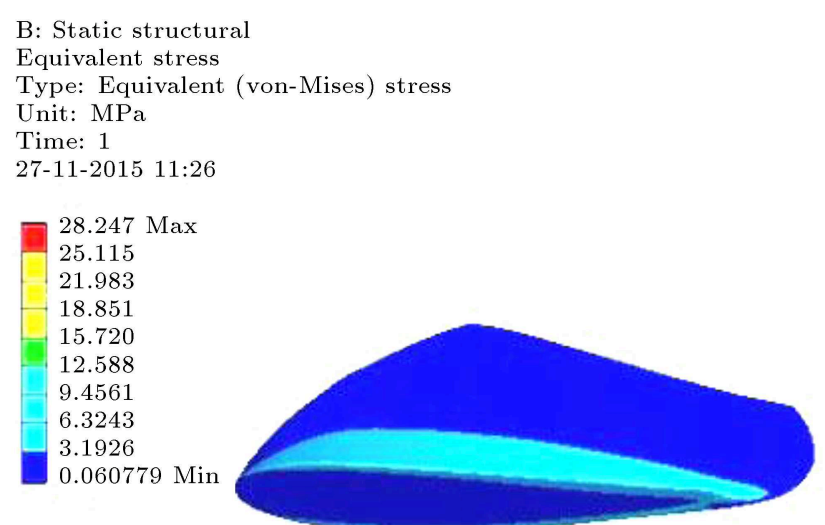

Figure 7. Equivalent (von-Mises) stress in the modeled blade.



Figure 8. Equivalent elastic strain in modeled blade.
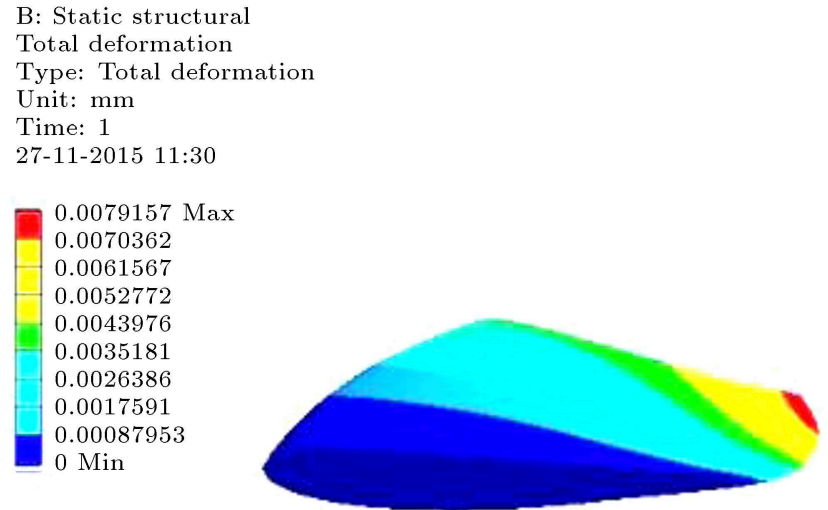

Figure 9. Total deformation in the modeled blade.

was then applied onto the blade surface for carrying out the stress analysis. The surface area of the entire blade was found to be $0.018 \mathrm{~m}^{2}$ and, therefore, the calculated surface force density was $69977 \mathrm{~N} / \mathrm{m}^{2}$.

Figures 7-12 show the analysis results of the stainless steel blade obtained using ANSYS 14.0

A similar procedure was adopted to obtain the values of different physical quantities of interest, i.e., equivalent stress, equivalent elastic strain, total deformation and the directional deformation for bronze alloy, copper alloy, and titanium alloy. 


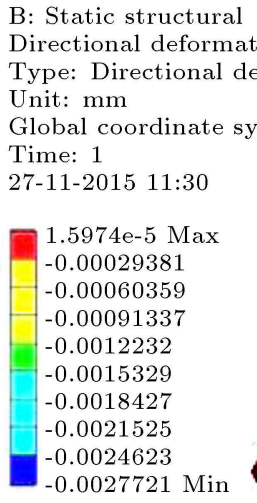

Figure 10. Directional deformation $(X$-axis) in the modeled blade.
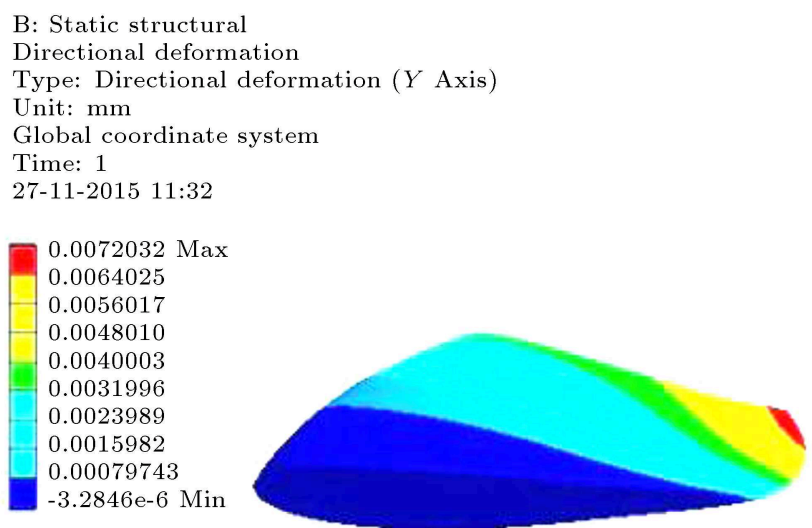

Figure 11. Directional deformation $(Y$-axis) in the modeled blade.

B: Static structural

Directional deformation

Type: Directional deformation ( $Z$ Axis)

Unit: $\mathrm{mm}$

Global coordinate system

Time: 1

27-11-2015 11:35
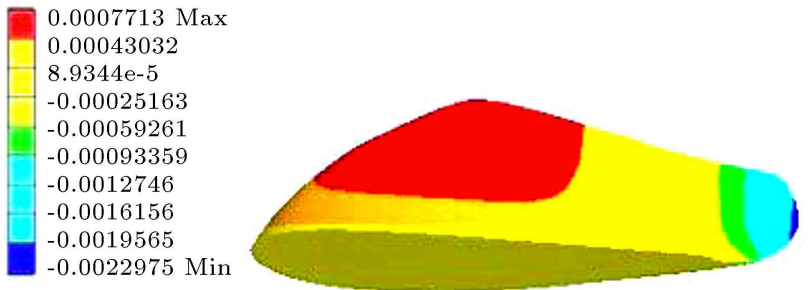

Figure 12. Directional deformation $(Z$-axis) in the modeled blade.

\section{Results and discussion}

The results of equivalent stress, equivalent elastic strain, and total deformation obtained were compared with respect to different construction materials of the modeled blade. The comparison results are shown in Figures 13-15.

As shown in Figure 13, the equivalent stress is the least in copper for the modeled blade, while it is

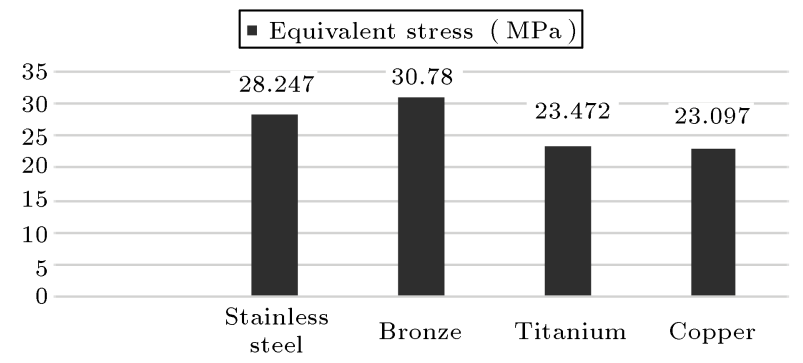

Figure 13. Comparison of equivalent stress for different construction materials of the blade.

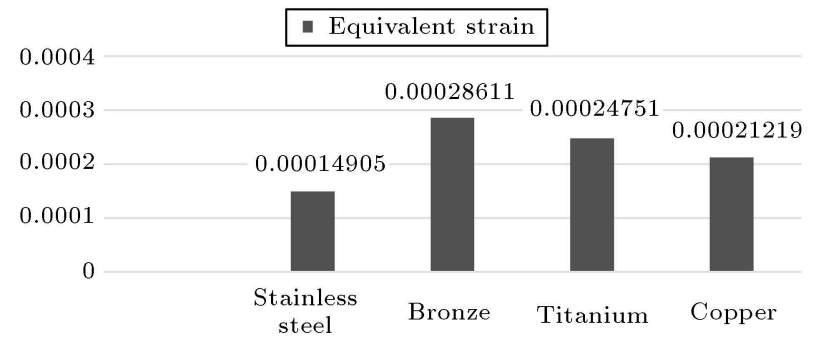

Figure 14. Comparison of equivalent strain for different construction materials of the blade.

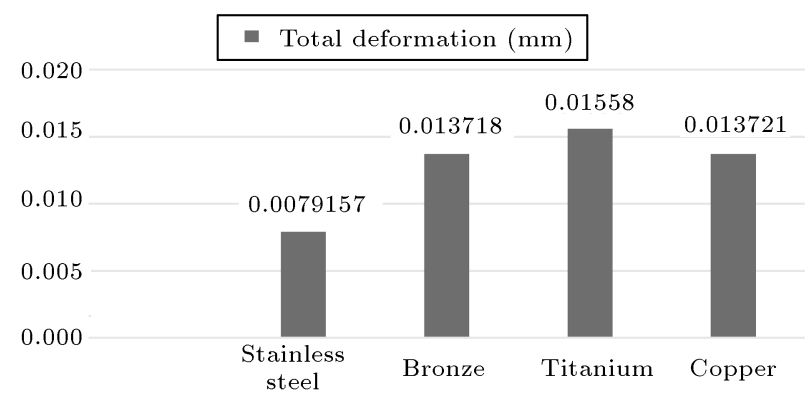

Figure 15. Comparison of total deformation for different construction materials of the blade.

maximum for stainless steel. The comparison of the equivalent strain results shows that the value is the least for stainless steel, whereas it is maximum for bronze. The comparison is shown in Figure 14. A quick glance at Figure 15 shows that the total deformation is the least for bronze and maximum for stainless steel. The variations in the equivalent stress, equivalent strain, and total deformation values may be attributed to different mechanical properties for different construction materials of the blade. Figure 16 shows the comparison of variations of equivalent stresses for different materials of the blade, designed using mean streamline theory and the free vortex theory.

Table 1 shows the results obtained for directional deformation in $X, Y$, and $Z$ axes for different construction materials of the blade. The results clearly show that the directional deformation is the least in the $X$ axis for different construction materials of the blade. The deformation in $Z$ and $Y$ axes is almost similar for different construction materials of the blade. The 
Table 1. Directional deformation for different construction materials of the blade.

\begin{tabular}{ccccc}
\hline Material & Stainless steel & Bronze & Titanium & Copper \\
\hline Directional deformation $X$-axis $(\mathrm{mm})$ & $1.590 \mathrm{e}-5$ & $2.935 \mathrm{e}-5$ & $3.540 \mathrm{e}-5$ & $2.930 \mathrm{e}-5$ \\
Directional deformation $Y$-axis $(\mathrm{mm})$ & 0.0072 & 0.0124 & 0.0141 & 0.0124 \\
Directional deformation $Z$-axis $(\mathrm{mm})$ & 0.0007 & 0.0013 & 0.0014 & 0.0013 \\
\hline
\end{tabular}

Table 2. Equivalent stress for different materials of the blade.

\begin{tabular}{ccccc}
\hline Material & Stainless steel & Bronze & Titanium & Copper \\
\hline Equivalent stress $(\mathrm{MPa})$ & 23.32 & 24.322 & 18.95 & 19.93 \\
\hline
\end{tabular}

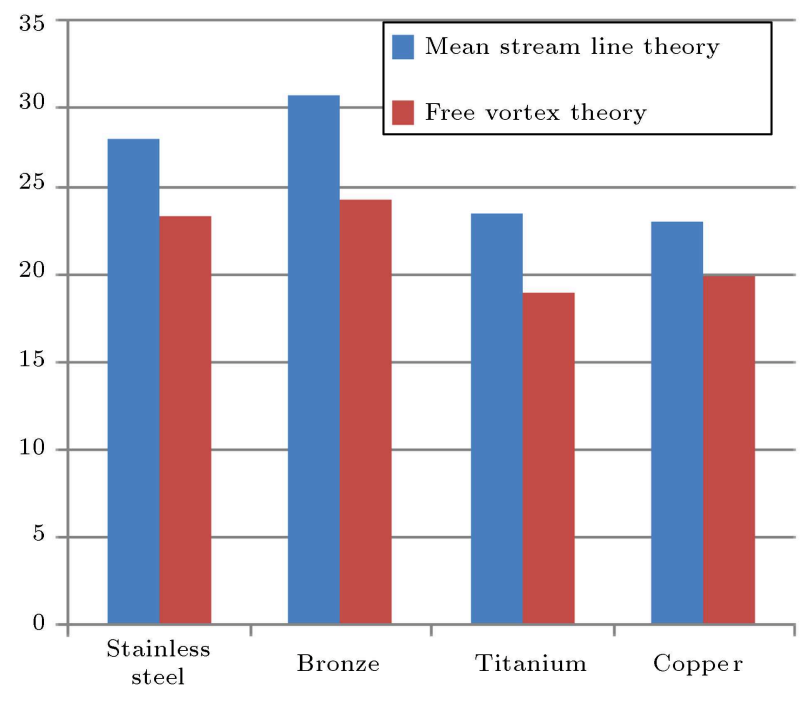

Figure 16. Comparison of variations of stress for different materials of the blade.

fact may be attributed to the geometric profile of the modeled blade.

Table 2 shows the equivalent stress for different materials of the blade, designed using free vortex theory [35].

\section{Conclusion}

In the present work, mixed flow pump impeller blade was designed using the almost unexplored mean streamline theory. The design process was carried out in AutoCAD 2013 and Solid Works Premium 2014 software and using ANSYS 2014 equivalent stress, equivalent elastic strain, total deformation, and the directional deformation was simulated for different construction materials of the blade, i.e., stainless steel, titanium alloy, bronze, and copper alloy. The various values obtained were compared with a blade designed using free vortex theory, a more commonly used model. The conclusions of the work can be summerized as below:

- The design of the impeller blade using mean streamline theory is comparatively more tedious and cum- bersome than designed using other design templates; however, the results are at par with other templates of design;

- According to the equivalent stress results, copper can be selected as a construction material of the modeled blade in the present work.

Since the stress in the titanium alloy blade is the least, according to the free vortex theory, one can select titanium as the material for the blade as part of the construction material considered in the present work.

The comparison of the variation of stresses shows that the stresses for the blade designed using mean streamline theory are always greater than those for the blade designed using free vortex theory. The difference in the stress area accounts for the difference in the stress values.

- The total deformation results show that the criterion of construction material selection for the modeled blade is considered, then titanium is more preferable to the other material of construction under study.

\section{Acknowledgement}

The authors sincerely acknowledge the comments and suggestions of the reviewers and the editorial board that have been instrumental in improving and upgrading this paper in its present form.

\section{Nomenclature}

A

$b$

Width $(\mathrm{mm})$

$C^{\prime} \quad$ Chord length $(\mathrm{mm})$

$D_{1 o} \quad$ Outlet blade diameter at hub (mm)

$D_{2 i} \quad$ Inlet blade diameter at tip ( $\left.\mathrm{mm}\right)$

$D_{2 o} \quad$ Outlet blade diameter at tip (mm)

$D_{i} \quad$ Diameter on the inlet side of the blade (mm)

$D_{m i} \quad$ Mean blade diameter at inlet $(\mathrm{mm})$ 
$D_{m o} \quad$ Mean blade diameter outlet $(\mathrm{mm})$

$D_{o} \quad$ Diameter on the outlet side of the blade $(\mathrm{mm})$

E $\quad$ Modulus of elasticity

$F \quad$ Shear force (N)

$H \quad$ Head of the pump (m)

I Moment of inertia $\left(\mathrm{mm}^{4}\right)$

$l \quad$ Length $(\mathrm{mm})$

$M \quad$ Bending moment (N-m)

$N \quad$ Rotational speed (rpm)

$N_{S} \quad$ Specific speed of the pump (rpm)

$P \quad$ Motor power $(\mathrm{kW})$

$Q \quad$ Volumetric flow rate $\left(\mathrm{m}^{3} / \mathrm{s}\right)$

$R \quad$ Radius of curvature of camber line (mm)

$S \quad$ Pitch $(\mathrm{mm})$

$T \quad$ Torque applied $(\mathrm{N}-\mathrm{m})$

$\tau \quad$ Shear stress $\left(\mathrm{N} / \mathrm{mm}^{2}\right)$

$U_{d} \quad$ Distortion energy density ( $\mathrm{W} \mathrm{m}^{3} / \mathrm{kg}$ )

$V_{S} \quad$ Velocity of $\operatorname{slip}(\mathrm{m} / \mathrm{s})$

$V_{\omega o} \quad$ Velocity of whirl at outlet $(\mathrm{m} / \mathrm{s})$

$y \quad$ Distance away from neutral axis ( $\mathrm{mm}$ )

$Y \quad$ Poisson's ratio

$Z \quad$ Number of blades

$\alpha_{m} \quad$ Mean blade angle (degree)

$\eta \quad$ Manometric efficiency

$\theta_{i} \quad$ Inlet fluid angle (degree)

$\lambda \quad$ Stagger angle (degree)

$\sigma_{b} \quad$ Bending stress $\left(\mathrm{N} / \mathrm{mm}^{2}\right)$

$\sigma_{V M} \quad$ Von-Mises stress $\left(\mathrm{N} / \mathrm{mm}^{2}\right)$

$\sigma_{y} \quad$ Yield stress $\left(\mathrm{N} / \mathrm{mm}^{2}\right)$

$\psi \quad$ Cone angle of the impeller (degree)

$\omega \quad$ Distributed load $(\mathrm{N} / \mathrm{m})$

$\Pi \quad$ PI (Radian)

\section{References}

1. Wislicenus, G.F., Fluid Mechanics of Turbomachinery, McGraw-Hill, New York (1947).

2. Myles, D.J. "A design method for mixed flow fans and pumps", Report No. 117, National Engineering (1965).

3. Stepanoff, A.J., Centrifugal and Axial Flow Pumps, 2nd Ed., John Wiley and Sons, New York (1957).

4. Neumann, B., The Interaction Between Geometry and Performance of a Centrifugal Pump, Mechanical Engineering Publications, London (1991).
5. Gahlot, V.K. and Nyiri, A., Impeller Pumps. Theory and Design, M.A.C.T, Bhopal (1993).

6. Varchola, M. and Hlbocan, P. "Geometry design of a mixed flow pump using experimental results of an internal impeller flow", Procedia Engineering, 39, pp. 168-174 (2012).

7. Zangeneh, M., Goto, A., and Takemura, T. "Suppression of secondary flows in a mixed flow pump impeller by application of three-dimensional inverse design method: Part 1 - design and numerical validation", ASME Trans. J. Turbomach., 118, pp. 536-543 (1996).

8. $\mathrm{Xu}$, J.Z. and $\mathrm{Gu}, \mathrm{C} . \mathrm{W}$. "A numerical procedure of three-dimensional design problem in turbo machinery", ASME Trans. J. Turbomach., 114, pp. 548-582 (1992).

9. Borges, J.E. "A three-dimensional inverse method for turbo machinery: Part-1 Theory", ASME Trans. J. Turbo, 112, pp. 346-354 (1990).

10. Peng, G., Cao, S., Ishizuka, M., and Hayama, S. "Design optimization of axial flow hydraulic turbine runner: Part I - an improved Q3D inverse method", International Journal for Numerical Methods in Fluids, 39, pp. 517-531 (2002).

11. Anagnostopoulos, J.S. "A fast numerical method for flow analysis and blade design in centrifugal pump impellers", Comput Fluids, 38, pp. 284-289 (2009).

12. Li, J., Zeng, Y., Liu, X., and Wang, H. "Optimum design on impeller blade of mixed-flow pump based on CFD", Procedia Eng., 31, pp. 187-195 (2012).

13. Jafarzadeh, B., Hajari, A., Alishahi, M.M., and Akbari, M.H. "The flow simulation of a low-specific-speed high-speed centrifugal pump", Appl. Math Model, 35, pp. 242-249 (2011).

14. Chaudhari, S.C., Yadav, C.O., and Damor, A.B. "A comparative study of mix flow pump impeller CFD analysis and experimental data of submersible pump", International Journal of Research in Engineering \& Technology (IJRET), 1(3), pp. 57-64 (2013).

15. Desai, S.M. and Naik, B.R. "Optimum design on impeller of mixed flow pump using CFD simulation", International Journal of Research in Engineering \& Technology, 4(8), pp. 535-537 (2015).

16. Mingxiong, O., Weidong, S., Weidong, J., and Qiang, F. "Numerical simulation and experimental validation on hydrodynamic radial force of mixed-flow pump impeller", Trans Chinese Soc. Agric. Eng., 31, pp. 7176 (2015).

17. Şakar, G. and Sabuncu, M. "Dynamic stability analysis of pretwisted aerofoil cross-section blade packets under rotating conditions", Int. J. Mech. Sci., 50, pp. 1-13 (2008).

18. Li, N., Zhou, Q., Chen, X., Xu, T., Hui, S., and Zhang, D. "Liquid drop impact on solid surface with application to water drop erosion on turbine blades, Part I: Nonlinear wave model and solution of onedimensional impact", Int. J. Mech. Sci., 50, pp. 15261542 (2008). 
19. Kaneko, S. and Hayashi, I. "Pressure pulsations in piping system excited by a centrifugal turbomachinery taking the damping characterstics into consideration", Journal of Fluids and Structures, 45, pp. 216-234 (2014).

20. Kikuyama, K., Hasegawa, H., and Maeda, T. "Unsteady pressure change in centrifugal pump impeller passages due to inlet swirl", Journal of Fluids and Structures, 6(3), pp. 337-351 (1992).

21. Shou-qi, P.Y., Jian-ping, Y., and Wen-jie, W. "The influence of the flow rate on periodic flow unsteadiness behaviors in a sewage centrifugal pump", Journal of Hydrodynamics, 25(5), pp. 702-709 (2013).

22. Pei, H., Dohmen, H.J., Yuan, S.Q., and Benra, F.K. "Investigation of unsteady flow-induced impeller oscillations of a single-blade pump under off-design conditions", Journal of Fluids and Structures, 35, pp. 89-104 (2012).

23. Langthjem, M.A. and Olhoff, N. "A numerical study of flow-induced noise in a two-dimensional centrifugal pump. Part I: Hydroacoustics", Journal of Fluids and Structures, 19(3), pp. 349-368 (2004).

24. Langthjem, M.A. and Olhoff, N. "A numerical study of flow-induced noise in a two-dimensional centrifugal pump, Part II: Hydroacoustics", Journal of Fluids and Structures, 19(3), pp. 369-386 (2004).

25. Rzentkowski, G. and Zbroja, S. "Experimental characterization of centrifugal pumps as an acoustic source at the blade-passing frequency", Journal of Fluids and Structures, 14(4), pp. 529-558 (2000).

26. Ramamurti, V. and Balasubramanian, P. "Steady state stress analysis of centrifugal fan impellers", Computers \& Structures, 25(1), pp. 129-135 (1987).

27. Jonker, J.B. and Essen, V.G.T. "A finite element perturbation method for computing fluid induced forces on a centrifugal impeller, rotating and whirling in a volute casing", International Journal for Numerical Methods in Engineering, 40, pp. 269-294 (1997).

28. Samir, L. and Nermina, Z. "Mode shapes of centrifugal pump impeller", Trends in the Development of Machinery and Associated Technology, B\&H, pp. 18-22 (2002).

29. Bhope, D.V. and Padole, P.M. "Experimental and theoretical analysis of stresses, noise and flow in centrifugal fan impeller", Mechanism and Machine Theory, 39(12), pp. 1257-1271 (2004).

30. Arewar, A.P. and Bhope, D.V. "Stress analysis of axial flow fan impeller", International Journal of Engineering Research and Applications, 3, pp. 2086-2090 (2013).

31. Das, A., Roy. A.K., and Kumar, K. "Design and stress analysis of a mixed flow pump impeller", International Journal of Mechanical Engineering and Computer Applications, 1(5), pp. 1-7 (2013).

32. Kan, K., Zheng, Y., Fu, S., Liu, H., Yang, C., and Zhang, X. "Dynamic stress of impeller blade of shaft extension tubular pump device based on bidirectional fluid-structure interaction", Journal of Mechanical Science and Technology, 31(4), pp. 1561-1568 (2017).

33. Kumar, A., Jain, K.K., Dave, R.K., and Choudhary, A. "CFD analysis of centrifugal pump impeller having different exit blade width, exit diameter and trailing edge blade angle to enhance performance", International Research Journal of Engineering and Technology, 4(5), pp. 1231-1239 (2017).

34. Kocaaslan, O., Ozgoren, M., Babayigit, O., and Aksoy, M.H. "Numerical investigation of the effect of number of blades on centrifugal pump performance", In AIP Conference Proceedings, 1863(1), pp. 1-4 (2017).

35. Srivastava, S., Roy, A.K., and Kumar, K. "Design of a mixed flow pump impeller blade and its validation using stress analysis", Procedia Mater Sci., 6, pp. 417424 (2014).

36. Horlock, J.H., Axial Flow Compressor - Fluid Mechanics and Thermodynamics, Butterworth Scientific Publications, London (1958).

37. Zindani, D., Roy, A.K., and Kumar, K. "Design of impeller blade of mixed flow pump: A comparative analysis", In Design and Optimization of Engineering Products, K. Kumar, and J.P. Davim, Eds., pp. 37-66, IGI Global, USA (2018).

38. Zindani, D., Roy, A.K., and Kumar, K. "Comparison of stresses in blade of a mixed flow pump impeller designed using mean stream line method and free vortex method", Materials Today: Proceedings, 4(8), pp. 9333-9340 (2017).

\section{Biographies}

Divya Zindani received BE in Mechanical Engineering, Rajasthan Technical University, Kota, ME in Design of Mechanical Equipment, BIT Mesra, and is presently pursuing $\mathrm{PhD}$ at the Department of Mechanical Engineering, National Institute of Technology, Silchar. He has over 2 years of industrial experience. His areas of interest are optimization, product and process design, CAD/CAM/CAE, and rapid prototyping. He has 1 patent, 2 books, 6 international journal, and 4 international conference publications to his credit.

Apurba Kumar Roy received BE (Mechanical Engineering, REC (now NIT), Jaipur), ME (Mechanical Engineering, Jadavpur University, Kolkata), and PhD (Engineering IIT Kharagpur). $\mathrm{He}$ is an Associate Professor at the Department of Mechanical Engineering, Birla Institute of Technology, Mesra, Ranchi, India. He has over 27 years of teaching, research, and industrial experience. His areas of interest are fluid dynamics, turbo machines, multi-phase flow, CFD, optimization and non-conventional energy, and direct energy conversion. He has 1 book, 3 book chapters, and 31 international journal, 5 international, and 15 
national conference publications to his credit. He is a member of the editorial board and review panel of 1 international journal of repute.

Kaushik Kumar received BTech (Mechanical Engineering, REC (now NIT), Warangal), MBA (Marketing, IGNOU), and PhD (Engineering, Jadavpur University). He is presently an Associate Professor at the Department of Mechanical Engineering, Birla Institute of Technology, Mesra, Ranchi, India. He has 14 years of teaching and research and over 11 years of industrial experience in a manufacturing unit of global repute. His areas of teaching and research interest are quality management systems, optimization, nonconventional machining, CAD/CAM, rapid prototyping, and composites. He has 9 patents, 5 books, 2 edited book volumes, 15 book chapters, 110 international Journal publications, and 18 international and 8 national conference publications to his credit. He is a member of the editorial board and review panel of 7 international and 1 national journals of repute. He has been felicitated with many awards and honors. 